\title{
A 29-year-old man with subcutaneous emphysema of the neck following blunt trauma
}

Published online: 31 March 2007

Dr. Peter Rosen: Today's case concerns a 29-year-old man who was riding his motorcycle down a quiet neighbourhood street. Someone had attached a chain from a tree on one side of the street to the other, because of an impending block party. The cyclist neither knew about the party, nor saw the chain. He collided with it at about 40 miles per hour. Someone saw him lying on the side of the road and activated the pre-hospital system by calling 911 .

L.D. Sanchez $(\bowtie) \cdot K . M$. Ban $・$ R. Wolfe $・$ P. Rosen

Department of Emergency Medicine

Beth Israel Deaconess Medical Center

Harvard Medical School

One Deaconess Road

West Campus Clinical Center, 2nd Floor

Boston, MA 02215, USA

e-mail: 1sanche1@bidmc.harvard.edu

K. Bramwell

Emergency Medicine of Idaho

St. Luke's Regional Medical Center

Boise, ID, USA

J.C. Sakles

Department of Emergency Medicine

University of Arizona College of Medicine

Tucson, AZ, USA

D. Davis

Department of Emergency Medicine

University of California San Diego Medical Center

San Diego, CA, USA
The paramedics found him lying supine with agonal respirations at a rate of $2 / \mathrm{min}$. His blood pressure was 150/100 $\mathrm{mmHg}$ and his pulse was 120 beats/min.

Their protocol allowed for oral intubation of an agonal patient, and they proceeded to intubate with a 7.5-mm tube without difficulty, after removing the cyclist's helmet carefully. However when they ventilated the patient with an Ambu bag, the neck puffed out with each inspiration, resembling that of a bullfrog. No breath sounds were heard.

They placed the patient on a backboard, with cervical spine precautions, and started two large bore peripheral IV lines en route.

At the Emergency Department (ED), the initial survey revealed a patient clothed in heavy motorcycle leathers, who was intubated, lying on a backboard and with a cervical hard collar in place.

After disrobing the patient, no obvious injuries were found other than for the neck, which had a linear discoloration about the level of the thyroid cartilage, with marked subcutaneous inflation with each breath.

No breath sounds could be heard in the chest. There was marked subcutaneous emphysema from the neck down to the midchest.

Dr. Sanchez would you like to begin this morning's airway forum for us?

Dr. Leon Sanchez: My initial thought based on the mechanism is that this man probably has an injury to his tracheobronchial tree. The fact that the neck filled with air with ventilations reinforces this [1]. I wonder what the paramedics saw when they intubated the patient. I find it hard to believe that this was a normal intubation and wonder if they saw anything unusual.

Dr. Rosen: All they saw were the arytenoid cartilages, but not the vocal cords. Nevertheless, they had no problem passing the tube. They just got this unusual expansion of 
the neck like a balloon inflating every time they tried to ventilate.

Dr. John Sakles: It is not surprising to me that what they saw during laryngoscopy was normal given that, based upon the mechanism, the injury is probably below the level of the vocal cords. I suspect the injury is further down the airway distal to where they were looking.

Dr. Richard Wolfe: They very likely placed the endotracheal tube through a laryngeal tear. Usually these tears are below the level of the cricothyroid membrane. This represents a difficult airway problem. Did you mention the oxygen saturation prior to arrival to the ED?

Dr. Rosen: No, I don't think they measured it. They were so fixed on the bullfrog effect. The oxygen saturation in the ED was in the low $70 \%$.

Dr. Kenny Bramwell: I would suspect that one of two things has happened. The patient seems to have a rather severe tracheal injury, and either they have passed the tube through the tear and are now insufflating air into the subcutaneous tissue or the injury was severe enough that there is a complete tracheal transection and the trachea has now receded into the thorax. Each time they insufflate air, it does not necessarily make it into the thorax, but instead goes preferentially into the subcutaneous tissue.

Dr. Wolfe: If this is, in fact, a complete tracheal tear where the distal tracheal stump has sunk down into the patient's chest, the patient is likely not viable. If it is, instead, a partial tracheal tear, there may be an opportunity to salvage the patient's life if one moves quickly. A surgical cricothyroidotomy is unlikely to be successful, leaving the operator with two options. The first option is to perform a fiberoptic bronchoscopy to visualise beyond the tear and pass the tube. The other option is to perform an immediate tracheostomy in the ED.

Dr. Kevin Ban: There is another possibility one might consider if challenged with this type of difficult airway. When blunt neck trauma results in a tracheal fracture, the lesion is usually below the level of the thyroid cartilage. It is either immediately below the cricothyroid membrane or down one or two interspaces. This is why one observes normal arytenoid and laryngeal anatomy when attempting an orotracheal intubation. My suggestion with these patients is to attack them surgically in the operating room. This will vary depending on what surgical capabilities your hospital has, and the availability of getting the patient immediately to an operating room. The distal stump of the fractured trachea usually does not retract into the mediastinum so long as the middle layer of the cervical fascia is intact. You need to keep this in mind as you approach these patients because while they need a surgical airway, the minute you make an incision into that cervical fascia you are going to open up the possibility of the fascial sling disappearing into the thorax. The distal stump may descend down where you will not be able to retrieve it without doing a median sternotomy.

Dr. Sanchez: I recommend securing the distal trachea through the skin with a skin hook or towel clip before you make your incision. In that way you have control of it so when you cut through the cervical fascia, the distal tracheal stump will not disappear into the thorax.

Dr. Rosen: This case was managed in the operating room. The patient was taken immediately to the operating room by the trauma surgeon who was able to respond to the trauma call simultaneously with the emergency physician. The oxygen saturation in the ED was about $70 \%$ so they were getting some oxygen through to the lungs, but not a sufficient amount. It was felt that this would not be a case that would be amenable to further oral manipulation. The paramedic endotracheal tube was left in place, and the patient was taken to the operating room where a vertical incision was made. Unfortunately they did not anticipate the problem that would occur, and as they made their incision the distal stump of the trachea retreated into the chest. They did an immediate median sternotomy, and were able to grasp the distal trachea, and perform an adequate surgical repair [2]. Fortunately the patient did not sustain any permanent hypoxic brain damage. It was a fortunate outcome, but the surgeon said that in the future, he would never do a tracheostomy in one of these patients without first having something holding on to the distal stump.

Dr. Wolfe: Where would you place your skin hook into the distal stump? Would you go as low down as possible because you do not know where the tear is?

Dr. Rosen: Often, it is possible to feel a deficit in the neck. I would take hold of it wherever I felt comfortable holding on to the distal stump. It does not matter if you put a hole in the tissue. You could also gain control by placing a sturdy OMersilene suture, but I think most of us have a skin or towel hook available that will allow one to grasp the stump.

Dr. Sakles could you comment on whether or not you would try a fiberoptic scope on a patient like this?

Dr. Sakles: The fiberoptic scope would be an excellent tool to use in managing this patient's airway. It was not clear to me initially where the position of the tube was relative to the wound upon arrival in the ED. It was entirely conceivable that the tracheal laceration was not complete, and that the patient was intubated in the trachea and air was recirculating back after each ventilation through that wound. By passing the fiberoptic scope through the tube you may have identified what and where the problem was [3]. If you 
emerge from the tube with the scope and see normal tracheal anatomy that you can follow down to the carina, you know that you are in good shape as the tear is proximal to this and your tube is in a good position. If you emerge from the tube with the scope and see a tracheal disruption then you are clearly proximal to the injury and you may be able to navigate the scope carefully past this into the distal trachea, and then advance the tube beyond the tracheal injury.

Dr. Ban: I suspect the endotracheal tube did not go beyond the tear. If it did go beyond the tear, I am not sure why you would get the bullfrog effect in the neck.

Dr. Rosen: In this particular case the tube was above the fracture, which was about the level of the first tracheal ring. I do not know what you would have seen with a fiberoptic scope. You might have seen normal tracheal rings distal and if you could get your scope down into the distal stump and get a tube passed down below the tear it would do the patient a great service. I am not sure you would be able to tell from inside the trachea with a partial tear where the tear would be. But it certainly might mechanically help you place the tube past the tear.

Dr. Sanchez: My concern is that this patient was extraordinarily unstable, and I do not know how quickly you can attain a satisfactory passage of a fiberoptic scope. This again is the kind of case where I would lean towards immediate surgical management, but again with the proviso of how you control the distal stump.
Dr. Sakles: Even though the patient is unstable, I think passing the scope through the tube can be done relatively quickly. It is much easier and faster than trying to scope a patient who is not yet intubated since the tube acts as a conduit for the scope. You can get a quick look and try to figure out where the injury is. I think there is tremendous benefit if there is something you can recognise, i.e., the tear, and try to mediate the situation by navigating past it. But I agree, in situations like these, where there is airway trauma with blood, and the patient is hypoxic, it can be very difficult to see anything at all.

Dr. Rosen: Again, this was a very difficult case. It turns out that the patient had no other injuries, which is curious because you would think this would be a great mechanism for cervical spine injury with the lever of the helmet on the neck, but in fact that was not the case. The patient actually did quite well once his airway was salvaged.

\section{References}

1. Goudy SL, Miller FB, Bumpous JM (2002) Neck crepitance: evaluation and management of suspected upper aerodigestive tract injury. Laryngoscope 112:791-795

2. Wu MH, Tseng YL, Lin MY, Lai WW (1997) Surgical results of 23 patients with tracheobronchial injuries. Respirology 2:127-130

3. Chen D, Edwards M (2006) Bronchoscopic diagnosis of an extensive tracheal laceration. ANZ J Surg 76:534-535 